\title{
Educação ambiental não formal: a experiência dos parques urbanos de Goiânia
}

\author{
Non-formal environmental education: the experience of urban parks of Goiânia
}

\section{Educación ambiental no-formal: la experiencia de los parques urbanos de Goiânia}

\author{
Ariana Cárita de Assis Marinho ${ }^{1}$ \\ Leandro Oliveira Gonçalves ${ }^{2}$
}

\begin{abstract}
Resumo
O enfrentamento dos problemas ambientais exige uma transformação na relação entre a humanidade e natureza. A educação ambiental não formal é uma estratégia importante para uma reintegração do ser humano ao ambiente, despertando sujeitos cidadãos, com consciência planetária, para intervir nas questões socioambientais. Nessa perspectiva, esta pesquisa, desenvolvida em sete parques da cidade de Goiânia, teve como objetivo estudar a educação ambiental nesses ambientes, avaliando a forma como as políticas públicas são consolidadas e explorando as percepções dos sujeitos vinculados a essas unidades. Trata-se de uma análise qualitativa por meio da categorização das respostas de questionários e entrevistas, além da análise de documentos da gestão pública municipal. Embora tenha se constatado uma percepção conflituosa entre natureza e ambiente, foi possível identificar elementos para ressignificação dos parques como espaços educativos para exercício da cidadania.
\end{abstract}

Palavras-chave: Educação ambiental não formal. Educação ambiental crítica. Parques urbanos.

\begin{abstract}
Facing environmental problems requires a transformation in the relationship between humanity and nature. Nonformal Environmental Education is an important strategy for a reintegration of the human being into the environment, awakening citizens with planetary consciousness to intervene in social and environmental issues. In this perspective, this research, developed in seven parks in the city of Goiânia, aimed to study environmental education in these environments, evaluating how public policies are consolidated and exploring the perceptions of the subjects linked to these units. It is a qualitative analysis through the categorization of the answers of questionnaires and interviews, besides the analysis of documents of the municipal public management. Although there was a conflicting perception between nature and environment, it was possible to identify elements for the re-signification of parks as educational spaces for the exercise of citizenship.
\end{abstract}

Keywords: Non-formal environmental education. Critical environmental education. Urban parks.

\section{Resumen}

El afrontamento de los problemas ambientales exige una transformación en la relación entre la humanidad y la naturaleza. La Educación Ambiental no formal es una estrategia importante para una reintegración del ser humano al ambiente, despertando personas ciudadanas, con conciencia planetaria, para intervenir en las cuestiones socioambientales. En esta perspectiva, esta investigación, desarrollada en siete parques de la ciudad de Goiânia, presentó como objetivo el estudio de la educación ambiental en estos entornos, evaluando la forma como las políticas públicas son consolidadas y explorando las percepciones de las personas vinculados a esas unidades. Se trata de un análisis cualitativa por medio de la categorización de las respuestas de cuestionarios y entrevistas, además del análisis de documentos de la gestión pública municipal. Aunque se constató una

\footnotetext{
${ }^{1}$ Doutoranda em Educação em Ciências e Matemática na Universidade Federal de Goiás. Técnica em Assuntos Educacionais no Instituto Federal de Goiás. Bolsista Fapeg de abril de 2014 a maio de 2016. E-mail: arianamarinho86@gmail.com
}

2 Doutor em Ciências Biológicas, Zoologia pela Universidade de São Paulo. Docente titular no Instituto de Ciências Biológicas da Universidade Federal de Goiás. E-mail: legospy@gmail.com 
percepción conflictiva entre naturaleza y ambiente, fue posible identificar elementos para la resignificación de los parques como espacios educativos para el ejercicio de la ciudadanía.

Palabras clave: Educación ambiental no formal. Educación ambiental crítica. Parques urbanos.

\section{Introdução}

A partir dos anos 1960, em meio a um contexto de grandes transformações sociais estabelecido após a Segunda Guerra Mundial, as terminologias formal / não formal / informal foram introduzidas nas discussões gerais e na educação em particular. Os sistemas escolares não eram capazes de suprir a alta demanda pela escolarização, além disso, se instaurou a contestação desses sistemas como instâncias de promoção social. Assim, as experiências não escolares ganham destaque na formação profissional e de cultura geral, como educação permanente de todas as idades em todos os aspectos da vida humana e de uma coletividade (FÁVERO, 2007).

Dessa forma, a partir do desenvolvimento teórico dessa questão tem-se que, em sentido amplo, a Educação pode ser concebida sobre três vertentes: formal, não formal e informal, sendo que o aspecto que marca a diferença entre as duas primeiras concepções e a última é a intencionalidade do processo (GOHN, 2014). Além disso, em contraposição à educação formal, a educação não formal (ENF) se mostra mais difusa, menos hierárquica e menos burocrática (GADOTTI, 2005). A ENF se consolida na aprendizagem e exercício de política e cidadania, capacitando os indivíduos a se tornarem cidadãos do mundo e no mundo (GOHN, 2006).

De acordo com Gohn (2006), a ENF está situada no campo da Pedagogia Social e se desenvolve em cenários constituídos coletivamente, a partir da intencionalidade das ações, da participação, do ensino ou da aprendizagem. E, ainda de acordo com essa mesma autora, atuando sobre aspectos subjetivos do grupo, a ENF pode, além das suas outras múltiplas vocações, despertar em um grupo a organização em torno de objetivos comunitários, para a solução de problemas coletivos cotidianos. Dessa forma, é possível almejar o fortalecimento da cidadania, como consequência de uma construção coletiva de relações sociais baseadas na igualdade e na justiça (GOHN, 2006).

Com esse mesmo foco na cidadania, a Educação Ambiental (EA) em uma perspectiva crítica, busca uma reflexão política e uma participação ativa dos sujeitos na melhoria do ambiente, através de uma leitura complexa da realidade (GUIMARÃES, 2004). Nesse sentido, a partir da articulação dessas duas concepções educativas, ou seja, a EA em circunstâncias não formais, seria possível vislumbrar uma transformação social através de um enfoque integral, que relacione o homem, a natureza e o universo, reportando à humanidade, de maneira reflexiva, suas responsabilidades pela degradação ambiental (JACOBI, 2003).

Embora não se objetive a substituição ou eliminação dos processos de EA da Educação Formal e reconhecendo as diferenças, vantagens e limitações das práticas em cada modalidade educativa, cabe ressaltar outro aspecto positivo de se trabalhar a EA em um contexto de ENF que é, segundo Guimarães e Vasconcelos (2006), a possibilidade de superação da armadilha paradigmática que aprisiona o ensino sobre questões ambientais nas escolas. De acordo com esse autor, as diversas funções sociais assumidas e a organização disciplinar da escola se apresentam como obstáculos para a reflexão de uma realidade complexa. Nesse sentido, ao se instituir em um espaço-tempo mais flexível e ao se mostrar mais próxima dessa complexidade, a ENF traz avanços na aquisição de uma cultura científica e na abordagem da EA (GUIMARÃES; VASCONCELOS, 2006).

$\mathrm{E}$, apesar do caráter menos burocrático da ENF, muitos dos documentos normativos que estruturam a EA no Brasil regulamentam essa modalidade educativa. E essa EA não 
formal (EANF) segue prevista nas diversas esferas administrativas brasileiras, sendo encontrada em documentos estaduais e também municipais, principalmente na perspectiva de atividades dentro das Unidades de Conservação (UC). A exemplo disso, a Política Nacional de Educação Ambiental (PNEA) destaca que EANF deve ser estimulada através da sensibilização da sociedade para a importância das unidades de conservação, dentre outros incentivos (BRASIL, 1999).

Nesse sentido, as UCs podem e devem ser espaço para a EANF, ou seja, práticas coletivas intencionalmente estruturadas, afastadas de uma disciplinaridade formal rígida e avaliações formais, além de um grande potencial na educação para a cidadania. Muitos dos programas de EA desenvolvidos em UCs pelas instituições gestoras dessas unidades contemplam uma perspectiva conservacionista, centrada em práticas educativas de contato com a natureza e distanciada das dinâmicas sociais e políticas (LOUREIRO; LAYRARGUES, 2013). Entretanto, é possível reconstruir o sentido das ações no intuito de reestabelecer as relações socioambientais historicamente desenhadas por conflitos, além do fortalecimento do desenvolvimento regional e a interação social nessas UCs (QUEIROZ, 2013). Reforçando, assim, o papel da EA como instrumento de inserção social, através de uma visão crítica relacionando a conservação ao uso público nessas UCs (PIMENTEL; MAGRO, 2014).

A condução da EANF, sob uma concepção crítica, em espaços protegidos por lei tem sido explorada de muitas formas e os estudos avançam no sentido de consolidar esses ambientes em seu potencial educativo. Na análise de Pimentel, França e Filho (2016) em uma UC da Amazônia Brasileira as atividades de EA permitiram a reflexão e o senso crítico sobre o ambiente, estimulando o exercício da cidadania dos participantes da pesquisa. Nessa mesma perspectiva, Queiroz e Guimarães (2016) ressaltaram que o parque, enquanto categoria de UC legalmente prevista, abriga motivações e interesses que conduzem a um maior envolvimento da sociedade e uma formação cidadã, que pode modificar a dinâmica socioambiental.

As UCs urbanas e propriamente os parques públicos se constituem no ideário de um uso que potencializa os desafios das práticas socioespaciais direcionadas para os sentidos de direito à cidade (BURGOS, 2015). Para Burgos (2015) o parque urbano apresenta uma série de fatores que potencializam ou constrangem as possibilidades de realização plena da esfera pública em estreita relação com a esfera política. Possibilidades, estas, determinadas pela magnitude das experiências de sociabilidade que advém do uso desses espaços no cotidiano.

Assim, UCs localizadas em um ambiente urbano despertam para a necessidade e potencialidade das atividades de EANF, uma vez que se encontram próximas a grandes grupos populacionais, que influenciam e são influenciados pelas características desse espaço público carregado de especificidades ambientais e sociais. Nesse contexto, foi desenvolvida uma pesquisa com o objetivo de estudar a EANF em UCs na cidade de Goiânia, avaliando de que forma políticas públicas são consolidadas nas UCs administradas pela prefeitura e explorando os aspectos das percepções dos sujeitos vinculados a essas unidades.

\section{Metodologia}

Esta pesquisa foi desenvolvida seguindo criteriosamente os princípios éticos para a pesquisa em Ciências Humanas, submetendo-se, portanto, ao Comitê de Ética. Os sujeitos que se voluntariaram a participar do estudo foram amplamente informados dos objetivos do trabalho e os riscos de sua participação, além disso, tiveram sua identidade preservada.

Nesta investigação priorizou-se a metodologia qualitativa da pesquisa em educação, que é caracterizada pelas múltiplas possibilidades de conhecer a realidade em um nível que não pode ser quantificado ou reduzido à operacionalização da realidade (MINAYO, 2001). Nesse tipo de metodologia, um aspecto importante é o foco no processo e não simplesmente 
nos resultados e produtos. Assim, os mecanismos qualitativos manifestam o modo como as experiências se traduzem nas atividades, procedimentos e interações do cotidiano, revelando as experiências do ponto de vista dos sujeitos da investigação, como aquilo que experimentam, o modo como interpretam as experiências e o modo como estruturam o mundo social em que vivem (BOGDAN; BIKLEN, 2006).

$\mathrm{Na}$ pesquisa qualitativa em educação os dados revelam a complexidade e a multidimensionalidade dos fenômenos, além disso, essa metodologia é capaz de evidenciar elementos importantes e subjetivos como o pensamento crítico e a criatividade (LUDKE; ANDRÉ, 1986). E, na educação o alcance do pensamento crítico se torna extremamente relevante, já que o papel de uma educação transformadora parte de um processo crítico e reflexivo, articulado com as questões políticas, sociais, econômicas, culturais e históricas, capaz de libertar e emancipar o ser (FREIRE, 1999).

Procurando atingir a complexidade da questão investigada, buscou-se a imersão nos documentos públicos sob a responsabilidade da Prefeitura Municipal de Goiânia, pretendendo, com isso, entender as políticas públicas e o discurso ambientalista da gestão municipal. E, a partir de então, perceber de que forma os elementos do discurso gerencial se articulam com as perspectivas da comunidade goianiense e como ocorre o desenvolvimento de práticas de EANF nas unidades estudadas. Para Marconi e Lakatos (2003), os documentos oficiais constituem a fonte mais fidedigna de coleta de dados, já as publicações administrativas, como por exemplo, as divulgações eletrônicas, devem levar em conta o momento político em que foram elaboradas.

Foi feito, inicialmente, um levantamento das intencionalidades e perspectivas da EANF concebida nas legislações em vigor, dentre elas a Lei Orgânica Municipal, o Plano Diretor da cidade, o Zoneamento Ecológico Econômico do Município de Goiânia, a Política Municipal de Educação Ambiental (PMEA) e a Minuta do Projeto de Lei que institui o Sistema Municipal de Unidades de Conservação. Além disso, essa investigação avançou pelas divulgações oficiais feitas pela prefeitura, principalmente aquelas publicadas na página eletrônica oficial da Agência Municipal de Meio Ambiente, durante o período de abril de 2015 a abril de 2016. E após esse processo, no intuito de organizar e estudar as informações obtidas, todos os trechos dos documentos que sinalizavam estratégias e previsões da EANF foram destacados e categorizados segundo seu objetivo: orientações, recomendações e obrigações.

Após o estudo da legislação e das publicações municipais, que deram uma noção geral da normatização e concepção da EANF no município, e para melhor compreender a forma com que a EANF tem sido efetivamente organizada nas unidades, estabeleceu-se um campo de trabalho que compreendeu sete parques municipais da cidade de Goiânia, capital do estado de Goiás, os quais estão relacionados, a seguir, de acordo com sua localidade na cidade: Região Central - Bosque dos Buritis e Parque Botafogo; Região Sudeste - Parque Carmo Bernardes; Região Sul - Jardim Botânico Amália Teixeira Franco, Parque Areião e Parque Vaca Brava; Região Noroeste - Parque Curitiba. Essas localidades foram selecionadas a partir das informações reveladas, por meio de entrevista, com representante do departamento de EA do órgão gestor municipal de Goiânia. De acordo com o gestor entrevistado, esses parques se destacavam como lócus de atividades de EA, enquanto nas demais UCs eram desenvolvidas poucas ou nenhuma atividade.

Foi feita a opção pelo uso do instrumento de entrevistas e questionários com a comunidade vinculada a essas UC, buscando entender as percepções dos sujeitos envolvidos nos processos e os meios pelos quais são elaboradas e desenvolvidas as atividades educativas. No decorrer das visitas aos parques foram identificados e se voluntariaram a participar da pesquisa 133 pessoas de diversos grupos de interesse, com múltiplas relações com os parques, ou seja, sujeitos que estabelecem vínculos com cada unidade amostrada ou simultaneamente 
com todas elas, influenciando e sendo influenciadas por essas UCs. Dessa forma, foram realizadas oito entrevistas com representantes do poder público que, de alguma forma contribuem para com a gestão dos parques, e o objetivo era identificar práticas e entender em que aspectos o poder público tem contribuído para o incremento de atividades de EANF nos parques goianienses. Por outro lado, para alcançar as percepções, as perspectivas e as ações de participação da comunidade usuária das UCs foram aplicados 125 questionários nas dependências dos sete parques, abrangendo vendedores ambulantes, guardas municipais e zeladores, esportistas, pessoas que se utilizam do parque para lazer e transeuntes.

A opção de uso de entrevistas com os gestores e questionários com os demais representantes da comunidade se deu pela viabilidade e logística para atender cada grupo pesquisado. As entrevistas e questionários partiram de temáticas similares, que abordavam desde questões de levantamento socioeconômico como idade, escolaridade e renda familiar até perguntas direcionadas à problemática da EA em si. Como exemplo disso, foi questionado aos participantes o que eles entendiam por Meio Ambiente e Natureza. Os voluntários também foram interpelados sobre o que entendiam por práticas de EA e lhes foi solicitado que fizessem um histórico sobre a participação em atividades nesse perfil, tanto no parque quanto em outros ambientes. Nos questionários e entrevistas também estavam presentes indagações sobre a relevância daquela UC visitada, tanto para os usuários quanto para o gestores e os desdobramentos para os seus contextos vivenciais.

A análise das informações obtidas com o estudo das legislações, publicações da gestão municipal, as respostas das entrevistas, questionários ocorreu pelo desenvolvimento de categorias de codificação. Essa análise foi norteada pelas orientações propostas por Bogdan e Biklen (2006), que entendem que à medida que os dados são auferidos, repetem-se ou destacam-se certas palavras, frases, padrões de comportamento, formas dos sujeitos pensarem e acontecimentos, desse modo, o pesquisador percorre os dados à procura de regularidades e padrões, estabelecendo, a partir dos tópicos identificados, as categorias de codificação ou a classificação dos dados descritivos recolhidos.

De maneira geral, as categorias de análise que emergiram dos dados, tanto dos documentos e publicações oficiais, quanto dos questionários e entrevistas, puderam ser organizadas a partir dos aspectos de concepções ambientais naturais, racionais, históricas ou generalizantes. Tais categorias foram elaboradas com base no suporte teórico de Tozoni-Reis (2004), assim como nas concepções de MA descritas por Sauvé (2005) e nas especificidades de uma Educação Ambiental Crítica ou Conservadora, com o suporte teórico de Guimarães (2004).

De acordo com as visões de natureza descritas por Tozoni-Reis (2004) e as concepções de MA descritas por Sauvé (2005), as concepções ambientais naturais denotam um caráter idílico da relação homem-natureza, destacando-se a nostalgia da natureza intocada, marcada por laços afetivos e poéticos; o sagrado para apreciar, respeitar e preservar. Nessa visão, o homem não faz parte da natureza. Já as concepções racionais revelam a natureza como fonte de recurso para o homem, ou seja, uma ética utilitarista. Nessa concepção, de viés antropocêntrico, o homem também é um agente externo da natureza e que dela se beneficia. As concepções históricas levam em conta as condições sociais, históricas, políticas, econômicas e culturais, reintegrando o homem à natureza, revelando um caráter de identidade. Por fim, as concepções generalizantes de ambiente emergem de discursos híbridos, vagos e não específicos, onde tudo é natureza.

\section{Resultados e Discussão}

Desde a década de 1980 os diversos gestores de Goiânia procuram alicerçar a imagem de uma cidade ecologicamente correta, ou a cidade dos parques e das flores. Para Oliveira (2008) essa valorização do discurso ambientalista foi reforçada pelas mudanças culturais 
manifestadas após o acidente radioativo, que ocorreu na cidade em 1987. E, além dos discursos, uma das ações da administração pública foi a criação e implantação de inúmeras áreas verdes, parques e bosques (OLIVEIRA, 2008).

As UCs implantadas na capital goiana, de maneira geral, recebem pouca atenção do poder público no que se refere à mobilização pela EANF. Apesar disso, nos sete parques amostrados nesta pesquisa foi possível constatar a existência de placas informativas, alertando, por exemplo, sobre a proibição de alimentação de animais e sobre a disposição incorreta de lixo. E, em duas das unidades existem, ainda, espaços e educadores designados pela prefeitura para o desenvolvimento de ações de EA. Mas, embora exista um discurso ambientalista privilegiado e homogêneo, por parte da gestão municipal, os parques goianienses, que dispõem de infraestrutura mínima para visitação, estão espacialmente concentrados nas regiões mais centralizadas da cidade. Assim, ao imprimir a imagem de uma cidade amplamente contemplada com as riquezas naturais dos parques, o poder público acaba por negligenciar a realidade vivida pelas periferias, tomando a parte pelo todo, ou idealizando positivamente a cidade a partir de seus fragmentos (SILVA; ALMEIDA, 2012).

Foi possível identificar, nas políticas públicas que regulamentam a EA em Goiânia e em específico na PMEA (GOIÂNIA, 2009), termos e conceitos que direcionariam o desenvolvimento da EA numa perspectiva mais crítica, propondo à população uma reflexão acerca da crise socioambiental instaurada. Como exemplo disso, tem-se a proposição de um conceito de meio ambiente abrangente e integrado, compreendendo suas vertentes históricas, ecológicas, psicológicas, políticas e econômicas, como nos trechos destacados a seguir:

Art. $4^{\circ}$ Os princípios básicos da Educação Ambiental são: [...]

II - a concepção do meio ambiente em sua totalidade, considerando a interdependência entre o meio natural, o socioeconômico, político e cultural, sob o enfoque da sustentabilidade; [...]

Art. $5^{\circ}$ Os objetivos fundamentais da Educação Ambiental no Município de Goiânia são: $[\ldots]$

II - o desenvolvimento de uma compreensão integrada do meio ambiente em suas múltiplas e complexas relações, envolvendo aspectos ecológicos, históricos, psicológicos, legais, políticos, sociais, econômicos, científicos, culturais, tecnológicos e éticos; [...] (GOIÂNIA, 2009, p.1).

Ainda, essa legislação prevê a participação cidadã como chave para o desenvolvimento de uma cidade socialmente sustentável. Essa compreensão integral do ambiente e o protagonismo cidadão são elementos estruturais da EA com orientação crítica, que propõe a superação da visão naturalista, que é focada na compreensão biológica e física do ambiente natural e na problematização dos impactos da ação humana sobre a natureza (CARVALHO, 2008). Na medida em que os sujeitos passam a se entenderem como parte do ambiente contextual e culturalmente determinado (SAUVÉ, 2005), a reflexão sobre os problemas ambientais adquire uma conexão com os conflitos sociais e, para superá-los há que se pensar em uma reforma multidimensional do conhecimento, dos valores culturais e éticos, das instituições e das relações sociais e políticas, não sendo possível acatar soluções práticas e reducionistas (LAYRARGUES; LIMA, 2014).

Mas, apesar dessa concepção histórica e integral de ambiente presente na legislação goianiense, identifica-se um conflito ideológico, já que de maneira geral, nas regulamentações que compõem o arcabouço normativo da EA e nas publicações eletrônicas oficiais do município, as ações de EANF são apresentadas como estratégias de sensibilização da comunidade em relação à conservação e preservação do mundo natural. Ou seja, a relação dos sujeitos com o ambiente, nessa perspectiva, tende a tornar-se unilateral contrapondo os seres humanos ao meio natural. É possível identificar essa perspectiva conservadora em vários trechos da legislação municipal e nas documentos públicos, como exemplificado no destaque 
a seguir retirado da página eletrônica oficial da Agência Municipal de Meio Ambiente de Goiânia, na divisão de Gestão Ambiental:

Com o objetivo de sensibilizar e informar a comunidade sobre mudanças de hábitos para construir uma cultura de cuidados com o meio ambiente de forma consciente, responsável e criativa, a gerência de educação ambiental, por meio de atividades lúdico-pedagógicas (teatro, palestras, oficinas de reaproveitamento, trilhas e informações sobre o meio ambiente), oferece à população as atividades: [...]

- Educação nos parques, objetivando a conscientização e a sensibilização para os cuidados com o meio ambiente; convivência harmoniosa da comunidade com o meio ambiente; posse responsável;

- Oficinas de reaproveitamento de resíduos sólidos;

- Palestras com temática ambiental: Cerrado, Água, Coleta Seletiva, Bacia do Rio

Meia Ponte, Aquecimento Global e conceitos básicos de educação ambiental.

- Exposição de matérias recicláveis [...] (AMMA, 2020).

Ao se estabelecer essa polarização, naturaliza-se o antagonismo, típico da sociedade, que é a humanidade versus a natureza (GUIMARÃES, 2011), contradizendo a concepção integral de ambiente, anteriormente proposta, e aproximando de práticas educativas mais conservadoras.

Para Guimarães (2004) essa EA é Conservadora por conservar o movimento de constituição da realidade, não superando o cientificismo cartesiano e o antropocentrismo, apoiando-se na relação desintegrada entre a sociedade e a natureza. As práticas pedagógicas da EA Conservadora são focadas na mudança de comportamento de cada indivíduo, ou seja, na terminalidade da ação e o conhecimento retido seria a garantia de um indivíduo transformado e, pela lógica que a sociedade é o resultado da soma de seus indivíduos, ocorreria também a transformação da sociedade (GUIMARÃES, 2004).

Em contraposição à EA Conservadora, a EA Crítica busca promover o questionamento às abordagens comportamentalistas, dualistas e reducionistas na relação cultura-natureza, incorporando, em seu fazer cotidiano, a completa contextualização da questão ambiental (LOUREIRO, 2004). O ambiente, nessa tendência conceitual, é ressignificado pela inserção do viés político, cultural e social e os problemas ambientais estão intimamente ligados aos conflitos sociais, ou seja, dentro de uma concepção histórica, trata-se da EA Popular, Emancipatória e Transformadora (LAYRARGUES; LIMA, 2014).

$\mathrm{Na}$ análise de D'Avila, Loureiro e Lamosa (2017), que teve como objeto de estudo a Política Municipal de Educação Ambiental do Rio de Janeiro, verificou-se que embora o poder público se aproprie de conceitos como crítica e transformadora, em suas políticas, com a perspectiva de atender demandas e reivindicações dos movimentos sociais, a política de EA atende a interesses gerenciais e mercadológicos da iniciativa privada. Tais interesses são percebidos quando da não destinação de verba para concretização das propostas e o estabelecimento de parcerias público-privadas, como estratégia para a criação e execução de projetos e a desburocratização dos processos, propiciando, assim, a propagação de conceitos conservacionistas, além da difusão e exposição das marcas das empresas (D'AVILA; LOUREIRO; LAMOSA, 2017).

Assim como na Política de Educação Ambiental do Rio de Janeiro, o documento norteador da EA de Goiânia apresenta a mesma tendência de convênios colaborativos com a iniciativa privada, refletindo uma temerária parceria que pode vir, em essência, a promover os interesses privados em vez de, com efeito, desenvolver uma reflexão da verdadeira causa da crise socioambiental, como no trecho a seguir destacado do Art. 15 da PMEA (GOIÂNIA, 2009):

Art. 15. [...]

Parágrafo único. Para fins do disposto no caput, o Poder Público Municipal incentivará:[...] 
III - a participação de empresas públicas e privadas no desenvolvimento de programas de educação ambiental em parceria com as escolas, as universidades e as organizações não governamentais; [...] (GOIÂNIA, 2009, p.2).

O entendimento verticalizado da EA presente na legislação e publicações, pautado na transformação individual, se reflete na ação, já que as práticas de EA, quando desenvolvidas pela prefeitura nos parques estudados, estão compreendias em um contexto de transmissão de conhecimento para alcançar a mudança de hábitos dos educandos, através da sensibilização e da harmonização com a natureza. Ainda, o público-alvo dessas atividades é essencialmente escolar, formado por crianças e jovens, estudantes da capital, como é possível perceber na resposta de um dos gestores, quando questionado sobre as atividades desenvolvidas no parque:

[...] O pessoal da AMMA traz as crianças, normalmente tem os colégios municipais, estaduais, até alguns particulares também, trazem as crianças, fala um pouco sobre o ecossistema, sobre a natureza, o que pode e o que não pode, ensinam algumas variedades de plantas, animais, aí fazem esse tipo de trabalho (GESTOR A, 2015)

Em consonância a esse apontamento sobre o foco da EANF realizada nos parques foi possível constatar que a maioria da comunidade usuária, $66 \%$ das pessoas que responderam aos questionários, alega nunca ter participado de uma atividade educativa dentro dos parques pesquisados. Contudo, uma parcela dos respondentes sinalizou a participação em práticas, por meio de iniciativas individuais ou coletivas, que de alguma maneira revelaram uma organização comunitária para o desenvolvimento de ações ligadas a EA, como é o caso nos seguintes apontamentos que emergiram dos questionários: "Nós organizamos e protestamos contra a derrubada das arvores feita pela prefeitura", conforme resposta do Usuário A (2015) e "Eu, juntamente com o pessoal da minha igreja, fazemos frequentemente um ato de adoração/oração, e em seguida realizamos uma atividade de limpeza do parque", resposta do Usuário B (2015).

Esses dados revelam o contrassenso entre os princípios norteadores de uma ENF e o público alvo do trabalho desenvolvido em Goiânia, composto de grupos específicos e essencialmente escolares, já contemplados com a educação formal. A EANF deve ser oportunizada a todos, indistintamente, atingindo todas as idades, pois tem um caráter permanente e dinâmico (REIGOTA, 2006). Nesse sentido, as ações educativas nos parques de Goiânia devem ser reorganizadas, juntamente com a sociedade, de modo a garantir o acesso a toda a comunidade nesse processo educativo.

Essa participação social, além de possibilitar a expansão do alcance das atividades, pode ser positiva em muitos outros aspectos, já que a EANF apresenta uma característica mais abrangente de EA comunitária ou popular, intimamente ligada aos processos de desenvolvimento social local, promovendo a capacidade de assimilar os problemas e avaliar as consequências ambientais das escolhas coletivas (CARVALHO, 2008).

A centralização da prática educativa com públicos escolares, percebida na fala dos gestores e no percentual de usuários que alegam nunca ter participado de atividades educativas nas unidades estudadas, difere dos resultados obtidos por Valenti et al. (2012), que analisaram as ações de EA presentes nas UCs brasileiras, gerenciadas pelo governo federal. Esses autores verificaram um público atendido irrestrito, possibilitando, dessa forma, superar as previsões de uma EA mais conservadora e comportamental, que prioriza o público infantil, na expectativa de que as crianças tenham papel decisivo no futuro (VALENTI et al., 2012).

$\mathrm{O}$ conflito entre homem e natureza, verificado nos documentos oficiais, nas publicações do município e nas práticas educativas, também é reconhecido na ideia de meio ambiente, que emerge das colocações da comunidade e dos gestores dos parques de Goiânia. Os sujeitos que participaram desta pesquisa, de maneira geral, reconhecem os parques como 
natureza intocada, lugar sagrado de refúgio da vida conturbada da cidade e fonte de recursos, que garantem uma vida humana saudável, conforme exemplificado nas falas dos Usuários $\mathrm{C}$ e D (2015), respectivamente: "A vida é muito estressante e corrida, e havendo lugares para ter contato com a natureza ajuda o homem a desacelerar o ritmo do dia a dia"; "O parque beneficia o clima e fatores climáticos em locais próximos à unidade, proporciona ambiente contemplativo, lúdico e espaço para passeios e caminhadas, refletindo isso, na saúde dos frequentadores".

Por certo que, no princípio os espaços de conservação foram, de fato, constituídos para manutenção de ecossistemas e recursos naturais, mantendo um caráter naturalizado do ambiente (QUEIROZ, 2013). No entanto, essa lacuna entre humanidade e natureza, que circunda a concepção de meio ambiente naturalizada pode ser superada através de uma EA mais crítica e reflexiva, reconstruindo o sentimento de pertencimento e explorando os estreitos vínculos entre identidade, cultura e natureza (SAUVÉ, 2005).

Buscando afastar essa visão naturalizada de ambiente, Reigada e Tozoni-Reis (2004) procuraram ampliar a compreensão de um grupo de crianças que participaram de uma pesquisa-ação, através da transmissão do conceito de ambiente numa perspectiva de espaço construído, ou seja, o mundo natural interligado com os sujeitos sociais. Já Machado (2009) propôs que os parques urbanos fossem tomados como espaços de discussões e práticas que estabeleçam transformações sociais. Para esse autor, o fato de o parque urbano compor a estrutura da cidade permite que os cidadãos tenham uma compreensão integral do todo, incluindo-se como parte integrante desse todo. Essa forma de encarar os parques se propõe a avançar sobre o reducionismo das práticas convencionais de educação, pelas quais as áreas verdes são encaradas como lócus de EA, naturais e isolados da esfera cultural. Outro ponto importante do trabalho de Machado (2009) é a proposição de uma mudança de perspectiva, pois costumeiramente, da implantação ao uso, o olhar é da cidade para o parque, mas o autor propõe a visão do parque para a cidade, assim, seria possível uma percepção alternativa e crítica dos modelos de ocupação, urbanização e desenvolvimento, além do esforço em ações coletivas conscientes e politicamente organizadas.

Nesse contexto, Loureiro e Cunha (2008) apontaram a EA Crítica e Emancipatória como uma estratégia para os conselhos de UCs, por entenderem que o papel de empoderamento dos grupos sociais e a justiça no acesso dos elementos naturais, promotores de satisfação material e simbólica, fortalecem o processo de gerenciamento ambiental, para além de uma prática administrativa. Nesse sentido, a EA é tratada de forma mais ampla, a de educação para a cidadania, que, mais do que o exercício dos direitos e dos deveres nas decisões políticas, também assegura ao sujeito total dignidade nas estruturas sociais (JACOBI, 2005). Desse modo, os grupos comunitários e os diversos usuários das UCs poderiam receber do poder público o incentivo e os princípios norteadores para a constituição de coletivos de EANF, revelando o potencial transformador da ENF e desencadeando práticas consolidadas em uma cidadania ativa.

Dentro desse pensamento, os sujeitos desta pesquisa demonstraram insatisfação com o processo de gerenciamento vigente através de uma reflexão acerca do desequilíbrio entre os parques situados nas áreas mais centrais e as unidades localizadas na periferia. Foram apontados aspectos de injustiça social na distribuição dos parques pela cidade, que estão concentrados nas regiões nobres, além da diferença na infraestrutura, que é mais precária nos poucos parques localizados em bairros periféricos, como apontam as falas de participantes Usuários E, F e G (2015) - respectivamente: "Só vejo parques como esse em bairros nobres e burgueses. Não sobra nada para a periferia"; "[...] muitos dos parques se encontram em áreas nobres, causando uma certa divisão social. É pelo fato da má gestão”; “[...] constroem parques na maioria das vezes apenas em áreas nobres, com intuito de valorizar imóveis". 
Henrique (2006) analisa a distribuição de áreas verdes nas cidades sob o viés da apropriação da natureza pelo mercado imobiliário. Para esse autor, os parques públicos se configuram, pela propaganda, em nichos de mercado e são explorados para a satisfação de desejos humanos, negando o acesso justo e igualitário aos cidadãos e transparecendo a ideia de bem privado. Esse processo de privatização se dá pelo fato de que, no período histórico atual, qualquer objeto associado à imagem de natureza simboliza qualidade de vida e transforma-se em valor econômico, elevando os preços dos imóveis (HENRIQUE, 2006). Nesse sentido, cria-se uma diferenciação espacial da natureza na cidade, de acordo com a segmentação social.

Embora o ambiente seja caracterizado nas políticas públicas como público, e exista a obrigatoriedade do Estado em assegurar esse caráter de bem comum, os aspectos constitutivos de uma sociedade desigual desvirtuam a ideologia das legislações. Para Jacobi (2003) existe, atualmente, uma demanda para que os cidadãos estejam motivados e engajados na mobilização e no questionamento do governo acerca da efetivação dessas políticas públicas. Assim, a reprodução do espaço público se dá ao passo que os socialmente desiguais se reinventam na autonomia e no protagonismo político (LOUREIRO, 2012).

Nesse aspecto, Zitkoski (2006) aponta para uma proposta de conceituação da cidade, em todas as suas dimensões, como projeto educativo voltado para a cidadania emancipatória, que se consolida na participação democrática e autêntica da sociedade como um todo. Dentro desse contexto, esse autor atribui à educação o papel de empoderar os cidadãos para que sejam capazes de construir uma nova cultura em relação aos aspectos políticos e sociais, no que se refere à coletividade e ao controle do bem comum.

Como o ambiente se traduz como bem comum a partir da justiça no acesso à riqueza $\mathrm{e}$ a natureza, o exercício da cidadania deve operar diretamente nessa segregação existente na estruturação do espaço urbano (CAVALCANTI, 2001). Desse modo, o justo acesso aos bens ambientais pode partir da formação através da EA crítica, que sustenta que a injustiça ambiental e as relações sociais alienadas são elementos estruturantes para a crise socioambiental estabelecida (LOUREIRO; LAYRARGUES, 2013).

Trata-se de uma crise dita socioambiental exatamente por traduzir o problema da sociedade urbana e industrial contemporânea, que está pautada na individualidade em detrimento da coletividade, suprindo as necessidades biológicas e socioeconômicas de poucos. A mesma lógica de apropriação dos parques pelo mercado imobiliário, como no caso estudado em Goiânia, está presente no cerne dos grandes conflitos entre as nações imperialistas e as nações pobres, entre os detentores da riqueza global e o restante da população mundial, pela exploração dos recursos. Como exemplo disso, podemos lançar um olhar crítico sobre as guerras de conquista de territórios ricos em petróleos, as crises internacionais pela escassez de água e as intenções por trás do enfrentamento entre países na defesa das florestas tropicais. Marques Filho (2016) avalia que a economia do planeta gira para satisfação da avidez de $8,4 \%$ de indivíduos da população mundial adulta, detentora de $83,3 \%$ da riqueza mundial, desencadeando uma máquina produtora de crises ambientais que beneficia a poucos.

Assim, a humanidade está composta, cada vez mais, de indivíduos isolados que rompem sua ligação com os outros indivíduos e com a natureza (GUIMARÃES, 2007). Nesse contexto, quando repensada sob um viés crítico e analítico, essa crise é entendida como um dos sinais do potencialmente destrutivo acúmulo de renda e o modo de produção que atende esse fim. Nesse sentido, as relações sociais conflituosas estabelecidas estão diretamente ligadas à degradação socioambiental. E, para um enfrentamento combativo, que busque atingir todas as circunstâncias da degradação socioambiental, é preciso pensar em um processo educativo amplo, que ultrapasse os muros das escolas, infiltrando-se em todos os 
setores sociais, promovendo uma nova relação entre a sociedade e a natureza (GUIMARÃES; PINTO, 2017).

\section{Considerações Finais}

A EA em um contexto não formal é uma importante estratégia para exercício da cidadania, possibilitando um trabalho abrangente e diversificado, no que diz respeito ao público envolvido e às múltiplas possibilidades de concepção do ambiente. Nesse sentido, a EA que acontece nos parques da cidade de Goiânia também apresenta um potencial educativo. Entretanto, esse potencial não tem sido explorado em toda a sua capacidade, visto que o poder público concentra os esforços em atividades voltadas para um público essencialmente escolar, composto por crianças e adolescentes, nos parques localizados nas regiões mais centralizadas da cidade. Além disso, as iniciativas populares são muito restritas, ligadas a ações pontuais e, por vezes, de cunho religioso, o que poderia potencializar, ainda mais, os discursos ligados a uma natureza sagrada e intocada.

Apesar dessa restrição das atividades, as políticas públicas goianienses, assim como as legislações de outras cidades brasileiras, se apropriam de conceitos norteadores e estruturantes para uma prática educativa crítica nos diversos tipos de UCs. No entanto, é possível perceber um conflito ideológico na própria legislação e na consolidação dessas políticas através das práticas desenvolvidas e nos planejamentos da gestão pública. Verifica-se nos documentos oficiais da cidade de Goiânia, principalmente na Política Municipal de Educação Ambiental, o fomento à parceria público-privada como meio de implementação de projetos e programas de EA.

Essas parcerias propiciam, conforme analisaram D'Avila, Loureiro e Lamosa (2017), a transmissão dos ideais mercadológicos da iniciativa privada, colocando o projeto pedagógico subserviente aos interesses do capital. Nessa perspectiva, em Goiânia as práticas de EA desenvolvidas nos parques, na maioria das vezes, são escassas e embasadas na sensibilização e transmissão de informações a um público específico, transparecendo uma tendência conservadora do processo educativo, divergindo dos princípios emancipatórios apresentados nos documentos oficiais.

Dentro dessa mesma ótica reducionista da EA, os sujeitos desta pesquisa revelaram uma concepção naturalizada do ambiente, a partir da idealização dos parques como refúgios de natureza intocada. Essa ruptura entre humanidade e natureza leva a um projeto preservacionista, em que o ser humano é o predador que deve ter seu comportamento domesticado através da EA. Dessa forma, apesar da relevância em detectar a interferência devastadora, há que se pensar nas causas da degradação ambiental como resultado das relações sociais constituídas e constituintes do modo de produção vigente (RODRIGUES; GUIMARÃES, 2010).

Os parques elencados neste estudo enfrentam diversas dificuldades ambientais provocadas pelas circunstâncias nas quais estão inseridos. Foram constatados, nos relatos dos sujeitos participantes da pesquisa, problemas referentes ao descarte inadequado de lixo por parte dos próprios frequentadores, a falta de manutenção, erosões decorrentes do escoamento pluvial inadequado, alimentação inapropriada dos animais que vivem nesses parques, pichações, danificações das árvores e equipamentos públicos. O grande desafio é articular a conservação com a pressão de expansão e desenvolvimento de Goiânia. Entretanto, exatamente por essa localização no centro urbano, os parques se revelam ricos espaços de exercício de uma cidadania ativa. Enquanto espaços socialmente construídos, devem ser encarados como centros de articulação cidadã de sujeitos analíticos e transformadores, que reproduzem suas ações para além dos limites desses parques. 
O compromisso com a EA está diretamente ligado ao comprometimento com a justiça ambiental e com a transformação política, social, econômica e cultural, de forma que os cidadãos tenham condições de agir no ambiente e pelo ambiente. Nesse sentido, é preciso que existam esforços para transformação dos espaços públicos como, por exemplo, os parques em verdadeiros laboratórios de cidadania ativa, que repercuta nas relações de todos e em toda a cidade.

\section{Referências}

AGÊNCIA MUNICIPAL DO MEIO AMBIENTE - AMMA Goiânia. Disponível em: <http:// http://www.goiania.go.gov.br/shtml/amma/atv_educativas.shtml >. Acesso em: 29 jul. 2020.

BOGDAN, R. C.; BIKLEN, S. K. Investigação Qualitativa em Educação. Tradução de Maria João Alvarez; Sara Bahia dos Santos e Telmo Mourinho Baptista. Porto: Porto Editora, 2006.

BRASIL. Lei n ${ }^{\circ}$ 9.7595, de 27 de abril de 1999. Dispõe sobre a educação ambiental, institui a Política Nacional de Educação Ambiental e dá outras providências. Diário Oficial da União, Brasília, DF, 28 abr., 1999. Seção 1, p. 41.

BURGOS, R. Espaços públicos e o direito à cidade: contribuições teórico-conceituais a partir de estudos sobre o uso dos parques urbanos em contextos de segregação espacial nas cidades de São Paulo e Sorocaba. Revista Cidades, Presidente Prudente, v. 12, n. 20, p. 105 - 140, 2015. Disponível em: 〈https://revista.fct.unesp.br/index.php/revistacidades/article/view/3949/3517>. Acesso em 15 mai. 2020.

CARVALHO, I.C.M. Educação ambiental: a formação do sujeito ecológico. 3. ed. São Paulo: Cortez, 2008.

CAVALCANTI, L.S. Uma geografia da cidade - elementos da produção do espaço urbano. In: CAVALCANTI, L.S. (Coord.). Geografia da cidade: a produção do espaço urbano de Goiânia. Goiânia: Alternativa, 2001. p. 11 - 32.

D’AVILA, E. C. P; LOUREIRO, C. F. B; LAMOSA, R. A. C. Políticas públicas educacionais: análise da Política de Educação Ambiental no município do Rio de Janeiro. Pesquisa e Debate em Educação, Juiz de Fora, v. 7, n. 1, p. 268 - 287, 2017. Disponível em:

<http://www.revistappgp.caedufjf.net/index.php/revista1/article/view/181>. Acesso em: 16 abr. 2018.

FÁVERO, O. Educação não formal: contextos, percursos e sujeitos. Educação e Sociedade, Campinas, v. 28, n. 99, p. 614 - 617, 2007. Disponível em: 〈https://www.scielo.br/pdf/es/v28n99/a17v2899.pdf〉. Acesso em: 14 mai. 2020.

FREIRE, P. Educação como prática da liberdade. 23 ed. Rio de Janeiro: Paz e Terra, 1999.

GADOTTI, M. A questão da Educação formal/não formal. In: DÔME MONDIAL POUR LES

ENFANTS, s/n, Sion, 2005. Anais... Bramois: Institut International des Droits de l'enfant - IDE, 2005. p. 1-11. Disponível em:

<https://aedmoodle.ufpa.br/pluginfile.php/305950/mod_resource/content/1/Educacao_Formal_Nao_F ormal_2005.pdf>. Acesso em: 26 ago. 2020.

GOHN, M. G. Educação Não Formal, Aprendizagens e Saberes em Processos Participativos. Investigar em Educação, Lisboa, s/v, n.1, p. 35-48, 2014. Disponível em: <http://pages.ie.uminho.pt/inved/index.php/ie/article/view/4/4>. Acesso em: 26 ago. 2020.

GOHN, M. G. Educação não formal, na pedagogia social. In: CONGRESSO INTERNACIONAL DE PEDAGOGIA SOCIAL, 1., São Paulo, 2006. Anais... São Paulo: FEUSP, 2006. s/p. Disponível em: 
$<$ http://www.proceedings.scielo.br/scielo.php?script=sci_arttext\&pid=MSC000000009200600010003 $4 \& \operatorname{lng}=\mathrm{en} \& \mathrm{nrm}=\mathrm{abn}>$. Acesso em: $20 \mathrm{Jan}$. 2020.

GOIÂNIA. Lei no 8.854 de 29 de outubro de 2009. Dispõe sobre a Política Municipal de Educação Ambiental e dá outras providências. Diário Oficial [do] Município de Goiânia. Goiânia, GO, 04 nov., 2009, n. 4.730, p 1.

GUIMARÃES, M. Educação Ambiental Crítica. In: LAYRARGUES, P. P. (Coord.). Identidades da educação ambiental brasileira. Brasília: MMA/DEA, 2004. p. 25-34. Disponível em: <www.mma.gov.br/estruturas/educamb/_arquivos/livro_ieab.pdf>. Acesso em: 26 ago. 2020.

GUIMARÃES, M. Educação Ambiental: Participação para além dos muros da escola. In: MELLO, S. S; TRAJBER, R. (Coord.). Vamos cuidar do Brasil: conceitos e práticas em educação ambiental na escola. Brasília: Ministério da Educação, Coordenação Geral de Educação Ambiental/ Ministério do Meio Ambiente Departamento de Educação Ambiental/ UNESCO, 2007. p. 85 - 93. Disponível em: < http://www.dominiopublico.gov.br/download/texto/me004660.pdf >. Acesso em: 16 abr. 2018.

GUIMARÃES, M. Armadilha paradigmática na educação ambiental. In: LOUREIRO, C. F. B.; LAYRARGUES, P. P; CASTRO, R. S. (Orgs.). Pensamento complexo, dialética e educação ambiental. 2. ed. São Paulo: Cortez, 2011. p. 15-29.

GUIMARÃES, M; VASCONCELOS, M. M. N. Relações entre educação ambiental e educação em ciências na complementaridade dos espaços formais e não formais de educação. Educar em Revista, Belo Horizonte, v. 22, n. 27, p. 147 - 162, 2006. Disponível em:

<https://revistas.ufpr.br/educar/article/view/6464> Acesso em 20 jan. 2020.

GUIMARÃES, M; PINTO, V. P. S. Alternativas para processos formativos de educação ambiental: a proposta da (com) vivência pedagógica diante de grandes e radicais desafios. Revista Eletrônica do Mestrado em Educação Ambienta, Rio Grande, Edição especial, s/v, s/n, p. 118-131, 2017. Disponível em: 〈https://periodicos.furg.br/remea/article/view/7146>. Acesso em: 16 abr. 2018.

HENRIQUE, W. A cidade e a natureza: a apropriação, a valorização e a sofisticação da natureza nos empreendimentos imobiliários de alto padrão em São Paulo. GEOUSP - Espaço e Tempo, São Paulo, s/v, n. 20, p. 65 - 77, 2006. Disponível em:

<https://www.revistas.usp.br/geousp/article/view/74008/77667 >. Acesso em: 16 mai. 2017.

JACOBI, P. Educação Ambiental, Cidadania e Sustentabilidade. Cadernos de Pesquisa, São Paulo, s/v, n. 118, p. 189-205, 2003. Disponível em: 〈www.scielo.br/pdf/cp/n118/16834.pdf〉. Acesso em: 26 ago. 2020.

JACOBI, P. Educação Ambiental: o desafio da construção de um pensamento crítico, complexo e reflexivo. Educação e Pesquisa, São Paulo, v. 31, n. 2, p. 233-250, Mai./Ago. 2005. Disponível em: <www.scielo.br/pdf/ep/v31n2/a07v31n2.pdf>. Acesso em: 26 ago. 2020.

LAYRARGUES, P. P; LIMA, G.F. da C. As macrotendências político-pedagógicas da Educação Ambiental Brasileira. Ambiente \& Sociedade, São Paulo, v. 17, n. 1, p. 23 - 40, 2014. Disponível em: $<$ http://www.scielo.br/scielo.php?pid=S1414-753X2014000100003\&script=sci_abstract\&tlng=pt $>$. Acesso em: 26 ago. 2020.

LOUREIRO, C. F. B. Trajetória e fundamentos da educação ambiental. São Paulo, Cortez, 2004.

LOUREIRO, C. F. B. Sustentabilidade e educação - um olhar da ecologia política. São Paulo: Cortez, 2012. 
LOUREIRO, C. F. B; CUNHA, C. C. Educação Ambiental e Gestão Participativa de Unidades de Conservação: Elementos para se pensar a sustentabilidade democrática. Ambiente \& Sociedade, São Paulo, v. 11, n. 2, p. 237 - 253, 2008. Disponível em: 〈www.scielo.br/pdf/asoc/v11n2/v11n2a03.pdf〉. Acesso em: 26 ago. 2020.

LOUREIRO, C. F. B; LAYRARGUES, P.P. Ecologia política, Justiça e Educação Ambiental Crítica: perspectivas de aliança contra-hegemônica. Trabalho, educação e saúde, Rio de Janeiro, v. 11, n. 1, p. 53 - 71, 2013. Disponível em: <http://www.scielo.br/scielo.php?script=sci_arttext\&pid=S198177462013000100004>. Acesso em: 26 ago. 2020.

LUDKE, M; ANDRÉ, M. Pesquisa em educação: abordagens qualitativas. São Paulo: EPU, 1986.

MACHADO, R. Parques urbanos como espaço de educação ambiental crítica: uma análise das experiências educativas do Parque Municipal Vila Guilherme - Trote, em São Paulo -SP. Gaia Scientia, João Pessoa, v. 3, n. 1, p. 71-80, 2009. Disponível em:

<http://www.periodicos.ufpb.br/index.php/gaia/issue/view/416/showToc>. Acesso em: 26 ago. 2020.

MARCONI, M. DE A.; LAKATOS, E. M. Fundamentos de Metodologia Científica. 5 ed. São Paulo: Atlas, 2003.

MARQUES FILHO, L. C. Capitalismo e Colapso Ambiental. 2 ed. Campinas: Editora da Unicamp, 2016.

MINAYO, M. C. S. (Org.). Pesquisa Social. Teoria, método e criatividade. 18 ed. Petrópolis: Vozes, 2001.

OLIVEIRA, E. C. de. O Acidente com Césio 137 e a Pós-modernidade em Goiânia. In: SERPA, E. C.; MAGALHÃES, S. M. (Orgs.). Histórias de Goiás: memória e poder. Goiânia: Ed. da UCG, 2008. p. $227-263$.

PIMENTEL, D. S; MAGRO, T. C. Diferentes dimensões da educação ambiental para a inserção social dos parques. Anais do Uso Público em Unidades de Conservação, Niterói, v. 2, n. 4, p. 1 - 9, 2014. Disponível em: <https://periodicos.uff.br/uso_publico/article/view/28730/16623>. Acesso em: 26 ago. 2020.

PIMENTEL, M. A. S; FRANÇA, C. F; FILHO, W. L. V. Educação Ambiental em área protegida na zona costeira da Amazônia brasileira. Delos, s/1, v. 9, n. 26, s/p, 2016. Disponível em: <www.eumed.net/rev/delos/26/educacion.html>. Acesso em: 26 ago. 2020.

QUEIROZ, E. E. Contribuições da Educação Ambiental Crítica para o uso público sustentável em Unidades de Conservação. Anais do Uso Público em Unidades de Conservação, Niterói, v. 1, n. 1, p. 1- 12, 2013. Disponível em: <https://periodicos.uff.br/uso_publico/article/view/28684/16642>. Acesso em: 26 ago. 2020.

QUEIROZ, E. D; GUIMARÃES, M. O trabalho de campo em Unidades de Conservação como ambiente educativo e estratégia pedagógica fundamental para uma formação diferenciada em educação ambiental. Revista Políticas Públicas da UFMA, São Luís, s/v, Número Especial, p. 421 - 425, 2016. Disponível em:

<http://www.periodicoseletronicos.ufma.br/index.php/rppublica/article/view/5994/3640>. Acesso em: 16 abr. 2018.

REIGADA, C.; TOZONI-REIS, M. F. de C. Educação ambiental para crianças no ambiente urbano: uma proposta de pesquisa-ação. Ciência \& Educação, Bauru, v. 10, n. 2, p. 149 - 159, 2004. 
Disponível em: <http://www.scielo.br/scielo.php?pid=S1516-

$73132004000200001 \&$ script=sci_abstract\&tlng=pt $>$. Acesso em: 26 ago. 2020.

REIGOTA, M. O que é Educação Ambiental. São Paulo: Brasiliense, 2006.

RODRIGUES, J. N; GUIMARÃES, M. Políticas públicas e educação ambiental na contemporaneidade: uma análise crítica sobre a Política Nacional de Educação Ambiental (PNEA). Ambiente e Educação, Rio Grande, v. 15, n.2, p. 13 - 30, 2010. Disponível em: <https://periodicos.furg.br/ambeduc/article/view/1009>. Acesso em: 16 abr. 2018.

SAUVÉ, L. Educação Ambiental: possibilidades e limitações. Educação em Pesquisa, São Paulo, v.31, n. 2, p. 317 - 322, 2005. Disponível em:

$<$ https://www.scielo.br/scielo.php?script=sci_arttext\&pid=S1517-

97022005000200012\&lng=pt\&tlng=pt>. Acesso em: 26 ago 2020.

SILVA, C. A; ALMEIDA, M. G. Parques públicos em Goiânia: paisagens de consumo e de representações sociais. Fragmentos de Cultura, Goiânia, v. 22, n. 3, p. 269 - 280, 2012. Disponível em: < http://seer.pucgoias.edu.br/index.php/fragmentos/article/view/2352>. Acesso em: 16 abr. 2018.

TOZONI-REIS, M. F. C. Educação Ambiental: natureza, razão e história. Campinas: Autores Associados, 2004.

VALENTI, M. W; OLIVEIRA, H. T; DODONOV, P; SILVA, M. M. Educação Ambiental em Unidades de Conservação: Políticas Públicas e a Prática Educativa. Educação em Revista, Belo Horizonte, v. 28, n. 01, p. 267 - 288, 2012. Disponível em:

<http://www.scielo.br/scielo.php?script=sci_arttext\&pid=S0102-46982012000100012 >. Acesso em: 26 ago. 2020.

ZITKOSKI, J.J. Educação e emancipação social: um olhar a partir da cidade educadora. Revista Espaço Pedagógico, Passo Fundo, v. 13, n. 1, p. 9 - 18, 2006. 